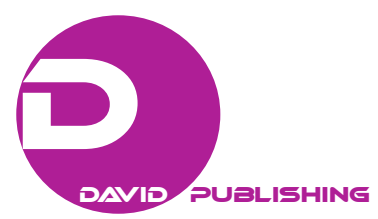

\title{
The Status Quo of Chinese International Business Practitioners' Intercultural Business Communication and Pedagogic Implications
}

\author{
JIAO Jing \\ Shanxi University, Taiyuan, China \\ XU Dejin \\ Sun Yat-sen University, Guangzhou, China
}

\begin{abstract}
We propose an intercultural business communication (IBC) model and design a questionnaire basing on the model to gain detailed knowledge on the status quo of 239 Chinese international business practitioners' IBC activities. The factual questions include the main working languages, the communication media applied, their high-frequency communication situations, communication scenarios important to organizations and employees' career life, the most challenging communication situations, and sensitive communication topics. Pedagogic implications are discussed basing on the survey findings.
\end{abstract}

Keywords: Chinese international business practitioners, intercultural business communication, status quo survey, pedagogic implications

\section{Introduction}

Communication is a need in today's business world (Palmer-Silveira, 2013, p. 9). Communication to the organizations is like blood to the body. Global companies are increasingly adopting new strategies striving to be more successful in the communication-based market of these days (Pikhart, 2014b, p. 952). Intercultural business communication (IBC) is the communication among individuals or groups from different cultural backgrounds in a business environment (Varner, 2000, p. 39). With the increasing opening up and globalization of China's economy, more international business practitioners have to take part in intercultural business communication activities to facilitate highly efficient international business. Intercultural business communication activities are widely found in all the industries and through the whole process of all international business activities. It takes place everywhere at anytime in international business. How about the status quo of Chinese international business practitioners' IBC? What are their high-frequency IBC scenarios? What are the most challenging IBC situations? The detailed and realistic information on their IBC is of great value to get the knowledge on the IBC competence required of international business students and key and difficult points in IBC pedagogy.

JIAO Jing, Ph.D, lecturer, School of Economics and Management Studies, Shanxi University, Taiyuan, China.

XU Dejin, Ph.D, professor, School of Foreign Languages, Sun Yat-sen University, Guangzhou, China.

Correspondence concerning this article should be addressed to Xu Dejin, School of Foreign Languages, Sun Yat Sen University, Postal code: 510275, No. 135 West Xingang Road, Guangzhou City, Guangdong, China. 


\section{Literature Review}

Communication is the transmitting of messages, thoughts, and affection among individuals (Peng \& Wang, 2014, p. 4). The communication process, together with elements involved, is depicted by different communication models, namely, the linear model, the cybernetic model, and the social systematic model from simple to complex, reflecting researchers' increasingly deep understanding about this important research field. The social systematic communication model incorporates not only the external social factors but also the communicators' internal psychological elements, which comprehensively illustrates elements involved in the dynamic communication process and the dialectical relationship between the communicators. Maletzke, Chen Guoming (2009, p. 23), and Huang Peilun (2016) are all proponents of this model.

Elements of communication are also proposed in communication models and one of those by Shannon-Weaver (1949) is representative: context, sender or encoder, message, medium, receiver or decoder, feedback, and noise. Chen Guoming (2009) argues that in a systematic communication model, nine elements are included: sender, encoding, message, channel, receiver, decoding, feedback, environment, and noise. Some definitions of IBC concern main elements involved in the IBC process in which characteristics of the communication scenarios and cultural differences of the two parts are highlighted. In the book Intercultural Business Communication by Lillian H. Chaney and Jeanette S. Martin, IBC is defined as communication within and between businesses that involves people from more than one culture (2013, p. 2). Iris Varner (2000) holds a similar opinion and proposes a theoretical model of IBC. The basic features of IBC are that the communication scenario is international business environment, the counterparts come from different cultural backgrounds, and communication activities take place among individuals or organizations.

The world-wide intercultural business communication is going on ceaselessly in the increasingly prosperous international business activities. New communication modes are continuously emerging and old modes are being upgraded or obsoleted, transforming the ecological landscape of IBC. New communication media and modes, together with increasing globalization, are making the IBC more convenient and efficient. Marcel Pikhart (2014a, p. 957) points out that modern communication technologies include Internet, e-mail, presentation software, and video-conferencing. Juan Carlos Palmer-Silveira (2013) discusses new trends in intercultural and international business communication: English as business lingua franca, genre analysis of business fax, e-mail, intercultural business conference, communication in international business events, business English curriculum design, the focus on intercultural communication competence in biz English textbooks, intercultural biz commercials, and so on.

Some Chinese scholars attempt to research the new features, research topics, and problems of IBC in the new media context (Liu, Gao, \& Ma, 2012; Wang, 2012). The popularity of Internet media has considerably expanded the time and space horizon of the traditional face to face IBC and transformed communication in both the real world and the virtual space. The message in communication is transmitted through e-mail, MSN, BBS, and other channels and many forms of communication are found such as QQ, Micro-blog, web page, website, Internet ads, and Internet shopping (Wang, 2012, p. 135). According to Liu Wei et al. (2012), the most common new media are Internet media, cell phone media, and mobile media.

\section{An Intercultural Business Communication Model}

The intercultural business communication is basically interpersonal communication situated in 
intercultural business settings, so the complexity of interpersonal communication is also reflected in intercultural business communication. Individuals' interpersonal communications are conditioned by specific cultural environment, situation, and interpersonal relationships and affected by individuals' objective, cognition, affection, motivation, and other factors (Zhang, 2003, p. 480). Intercultural business communication activities are also influenced by individuals' psychological factors of cognition, affection, attitude and motivation, and the external intercultural biz environment and complex social cultural conditions such as specific biz communication scenarios, biz communication counterparts, biz communication modes, and genres of biz texts.

Based on the systematic communication model, we propose a definition of intercultural business communication: It is the face-to-face or media-based interpersonal communication of information, thoughts, and affection between or among international business practitioners from different cultural backgrounds in order to realize their business or rapport objectives. A dynamic and dialectical intercultural business communication model is established as in Figure 1, in which seven elements are included: communication objective, communication situation, message sender, receiver, message, communication channel or media, and feedback.

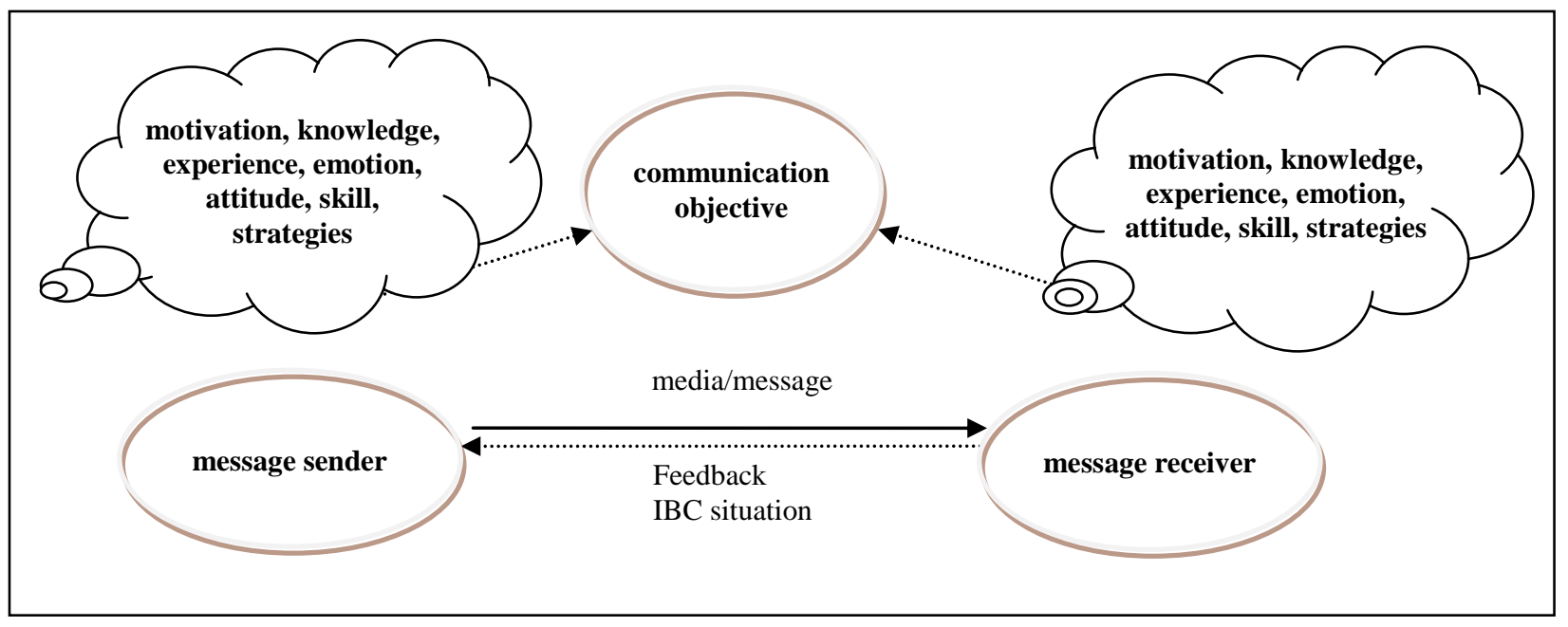

Figure 1. An intercultural business communication model.

Business communication links practitioners' business activities. The communication objective is negotiated once the two parties have communication needs and motivations. Business and rapport objectives are included in the communication objective. The business objective is the engine that launches and promotes the communication. The IBC situation defines the communication activities with the visible physical conditions of time, space, occasion, and invisible socio-cultural psychological conditions such as communicators' identity and relationship. International business practitioners' daily communication activities are composed of different series of communication events featured by specific topics, communication objectives, participants, communication modes, and communication media. The intercultural biz communication is realized and accomplished with different communication events. Under different communication topics, the communication events reflect and depict the existence of communication activities. In the workplace, business practitioners experience complex and various communication events and need to readily shift from one event to another. During the communication process, the message is transmitted dynamically in two ways from the sender to the receiver and vise versa. The message of the sender and the receiver is not only the cause but also the result of 
the communication behaviors of the two parts, which are closely related in a cause-consequence order. The sender usually launches the communication and the receiver often provides feedback to the sender. Since the feedback also provides information for the sender, the feedback is the message sent out by the "sender", the receiver. The receiver, the original sender, then, after analyzing the useful information, affection, attitude, and thoughts, decides the message and communication strategies for the next round of communication. So the role of the sender and the receiver is dialectical and the two parts change their roles alternatively: They are both sender and receiver, encoder and decoder. The two parts are also carriers of intercultural business communication competence, whose motivation, knowledge, experience, emotion, attitude, and skills are the software necessary for successful communication. In the dynamic communication process, the partners are situated in the exchange flow of information, affection, and thoughts and dynamically apply their knowledge, experience, strategies, and skills to express motivation, emotion, attitudes, and opinions to realize effective and appropriate intercultural business communication. The knowledge, especially the cultural and business knowledge is the information that the communicator needs to apply at any time during the communication. The communication and intercultural strategies facilitate the smooth proceeding of the business communication. The business strategies ensure the realization of organizational and individual objectives and effectiveness of communication. Modern communication technologies and media serve as hardware for smooth and efficient communication.

International business practitioners have to take part in various business communication events in which they play different roles and adjust their communication behaviors flexibly according to their changing roles. Although the communication counterparts may differ, their biz communication activities are similar. The knowledge on the status quo of their IBC may shed some light on the IBC pedagogy. To address this question, the authors design a survey to investigate the current situation.

\section{The Survey and Results}

A questionnaire was developed on the basis of the above-mentioned IBC model. The survey was administered through wjx.cn from April to August, 2017. 239 questionnaires were filled, with 235 valid responses. Factual questions in the questionnaire were designed basing on key elements in the model. Besides the demographic information of the respondents, the factual questions cover the language used in the workplace, communication modes, communication media, high-frequency communication scenarios, the communication situations important to organizations and employees' career life, the most challenging communication situations and sensitive communication topics. The respondents' demographic information is shown in Table 1.

The working languages of $40.85 \%$ of the respondents are both English and Chinese. English is mainly used by $16.17 \%$ and Chinese is mainly used by $41.28 \%$ of the practitioners. In total, English is used by $57.02 \%$ of the international biz people in this survey. Face to face communication is the main communication mode of $18.72 \%$ of the practitioners while $29.79 \%$ of them are mainly involved in media-based communication. $51.49 \%$ of the subjects apply both the modes. So the media-based communication is the main mode of communication of the Chinese biz practitioners in the survey. The high frequency intercultural biz communication media are e-mail, telephone or cell phone, We-Chat, QQ, PPT, and teleconference. This finding lends support to the research by Marcel Pikhart (2014a, p. 955) who argues that the current reality of business communication is based almost purely on electronic interaction with people from other cultures, backgrounds, nations, and continents. The high frequency IBC scenarios are ranked as e-mail communication, conference communication, 
telephone communication, biz reception, job interview, biz negotiation, and PPT presentation. Conference communication, e-mail communication, and business reception are the top three communication situations important to the subjects' organizations. Other important situations are phone call communication, biz negotiation, and job interviewing. The conference communication, interview communication, and business reception are considered to be top three important communication situations to the subjects' career life. E-mail communication, biz negotiation, phone call communication, and PPT presentation are also ranked as important situations. The challenging communication situations are rated as business conference, business negotiation and business reception, job interview, phone call communication, e-mail communication, and PPT presentation. The topics of price negotiation, pay rise, and customer complaints rank the top three sensitive and challenging communication issues. Next come the topics of promotion, working overtime, and asking for a leave.

Table 1

Respondents’ Demographic Profile

\begin{tabular}{|c|c|c|c|}
\hline Stat item & Information & Number & Frequency $(\%)$ \\
\hline \multirow{3}{*}{ Gender } & Male & 85 & 36.17 \\
\hline & Female & 150 & 63.83 \\
\hline & Total & 235 & 100 \\
\hline \multirow{6}{*}{ Age } & $20-30$ & 83 & 35.32 \\
\hline & $31-40$ & 117 & 49.79 \\
\hline & $41-50$ & 28 & 11.9 \\
\hline & $51-60$ & 6 & 2.55 \\
\hline & $>60$ ys & 1 & 0.43 \\
\hline & Total & 235 & 100 \\
\hline \multirow{7}{*}{ Affiliation } & State-owned & 60 & 25.53 \\
\hline & Joint-venture & 19 & 8.09 \\
\hline & $\begin{array}{l}\text { Foreign-own } \\
\text { ed }\end{array}$ & 32 & 13.62 \\
\hline & Cooperative & 2 & 0.85 \\
\hline & $\begin{array}{l}\text { Private } \\
\text { enterprise }\end{array}$ & 63 & 26.81 \\
\hline & Other & 59 & 25.11 \\
\hline & Total & 235 & 100 \\
\hline \multirow{8}{*}{$\begin{array}{l}\text { Linguistic } \\
\text { proficiency } \\
\text { level }\end{array}$} & CET4 & 40 & 17.02 \\
\hline & CET6 & 47 & 20 \\
\hline & TEM4 & 4 & 1.7 \\
\hline & TEM8 & 85 & 36.17 \\
\hline & TOFEL & 6 & 2.55 \\
\hline & IELTS & 9 & 3.83 \\
\hline & Other & 44 & 18.72 \\
\hline & Total & 235 & 100 \\
\hline
\end{tabular}

\begin{tabular}{|c|c|c|c|}
\hline Stat item & Information & Number & Frequency $(\%)$ \\
\hline \multirow{6}{*}{$\begin{array}{l}\text { Working } \\
\text { years }\end{array}$} & $<3$ ys & 66 & 28.09 \\
\hline & $3-5$ years & 15 & 6.38 \\
\hline & $6-8$ years & 18 & 7.66 \\
\hline & 9-11years & 27 & 11.49 \\
\hline & $>11$ ys & 109 & 46.38 \\
\hline & Total & 235 & 100 \\
\hline \multirow{11}{*}{ Industry } & Translation & 13 & 5.53 \\
\hline & Pharmacy & 5 & 2.13 \\
\hline & Manufacture & 55 & 23.4 \\
\hline & Education & 62 & 26.38 \\
\hline & Exhibition & 2 & 0.85 \\
\hline & Logistics & 18 & 7.66 \\
\hline & Finance & 12 & 5.11 \\
\hline & Consulting & 5 & 2.13 \\
\hline & Tourism & 2 & 0.85 \\
\hline & Other & 61 & 25.96 \\
\hline & Total & 235 & 100 \\
\hline \multirow{4}{*}{ Position } & Primary staff & 14 & 48.51 \\
\hline & Middle manager & 103 & 43.83 \\
\hline & Top manager & 18 & 7.66 \\
\hline & Total & 235 & 100 \\
\hline \multirow{7}{*}{$\begin{array}{l}\text { Number of } \\
\text { trips abroad }\end{array}$} & Null & 111 & 47.23 \\
\hline & $<3$ times & 61 & 25.96 \\
\hline & 3-5times & 33 & 14.04 \\
\hline & 6-8times & 11 & 4.68 \\
\hline & 9-11 times & 4 & 1.7 \\
\hline & $>11$ times & 15 & 6.38 \\
\hline & Total & 235 & 100 \\
\hline
\end{tabular}




\section{Pedagogic Implications}

The survey findings provide implications for IBC pedagogy. $57.02 \%$ of the respondents use English as their working language. So English is widely utilized by Chinese international biz professionals in the survey. Biz English teaching should still be stressed in IBC pedagogy including biz English listening, speaking, reading, writing, and translating. Modern medium-based communication dominates the biz communication activities. Written (in e-mail communication, for example) and oral (in conference, negotiation, reception, job interview, and phone call communication, for example) are two important modes of communication, which should be included in e-mail, phone call, PPT presentation, and teleconference communication pedagogy and the discourse features need to be analyzed for biz students. The most challenging communication scenarios are almost oral, face-to-face communication situations where the respondents feel more pressure and less communication efficacy, so the students' competence of handling these situations should be strengthened including the awareness and cognition about the oral genres in different situations, their application competence, and oral communication practice. The situation-based pedagogy idea should guide the teaching which highlights the features of diverse communication situations and stylistic characteristics of the discourse in different contexts. More practice and training is needed for the challenging communication topics by introducing the techniques of simulation, role play, and case analysis to make students sensitive to, familiar with, and adaptable to the topics. To facilitate communication activities, intercultural training is also needed to promote students' cultural intelligence including their meta-cognition $\mathrm{CQ}$, cognition about the required cultural knowledge and communication style; the verbal and non-verbal behavioral ability; flexibility in adjusting communication behaviors according to the partners' different cultural backgrounds and business topics and communication motivation on intercultural business communication confidence and efficacy.

\section{References}

Chaney, L. H., \& Martin, J. S. (2013). Intercultural business communication. Beijing, China: China Renmin University Press.

Chen, G. M. (2009). Foundations of intercultural communication. Shanghai, China: East China Normal University Press.

Huang, P. L. (2016). Organizational behavior. Guangzhou, China: South China University of Technology Press.

Liu, W., Gao, C., \& Ma, H. (2012). Intercultural business communication in the time of new media. News and Writing, (8), 43-45.

Palmer-Silveira, J. C. (2013). Editorial: The need for successful communication in intercultural and international business settings: Analytic and comparative studies, new trends and methodologies. Iberica, 26, 9-16.

Peng, K. P., \& Wang, Y. L. (2014). Psychology of cross-cultural communication. Beijing, China: Beijing Normal University Publishing Group.

Pikhart, M. (2014a). New horizons of intercultural communication: Applied linguistics approach. Social and Behavioral Sciences, $152,954-957$.

Pikhart, M. (2014b). Implementing new global business trends to intercultural business communication. Social and Behavioral Sciences, 152, 950-953.

Varner, I. (2000). The theoretical foundation for intercultural business communication, a conceptual model. Journal of Business Communication, 37(1), 39-57.

Varner, I., \& Beamer, L. (2014). Intercultural communication in the global workplace. Dalian, Liaoning, China: Dongbei University of Finance and Economics Press.

Wang, S. L. (2012). The evolution of intercultural business communication research in the Internet environment. Academic Exchange, (2), 134-137.

Zhang, S. H. (2003). A study of the structure and the measurement on communication competence of enterprise manager. Shanghai: East China Normal University. 